\title{
Effects of acetyl-DL-leucine in patients with cerebellar ataxia: a case series
}

\author{
Michael Strupp · Julian Teufel • Maximilian Habs · Regina Feuerecker • \\ Carolin Muth • Bart P. van de Warrenburg • Thomas Klopstock • \\ Katharina Feil
}

Received: 12 June 2013/Revised: 17 June 2013/ Accepted: 18 June 2013/Published online: 9 July 2013

(C) The Author(s) 2013. This article is published with open access at Springerlink.com

\begin{abstract}
No existing medication has yet been shown to convincingly improve cerebellar ataxia. Therefore, the identification of new drugs for its symptomatic treatment is desirable. The objective of this case series was to evaluate the efficacy of treatment of cerebellar ataxia with the amino acid acetyl-DL-leucine (Tanganil). Thirteen patients (eight males, median age 51 years) with degenerative cerebellar ataxia of different etiologies (SCA1/2, ADCA, AOA, SAOA) were treated with acetyl-DL-leucine $(5 \mathrm{~g} /$ day) without titration for 1 week. Motor function was evaluated by changes in the Scale for the Rating and Assessment of Ataxia (SARA) and in the Spinocerebellar Ataxia Functional Index (SCAFI) during treatment compared to a baseline examination. Quality of life (EuroQol5D-3L) and side effects were also assessed. Mean total SARA decreased remarkably $(p=0.002)$ from a baseline
\end{abstract}

Michael Strupp and Julian Teufel contributed equally to this manuscript.

M. Strupp $(\bowtie) \cdot$ J. Teufel · M. Habs · R. Feuerecker .

C. Muth · T. Klopstock · K. Feil

Department of Neurology, University Hospital Munich and

German Center for Vertigo and Balance Disorders, Campus

Grosshadern, Marchioninistrasse 15, 81377 Munich, Germany

e-mail: michael.strupp@med.uni-muenchen.de

J. Teufel

e-mail: julian.teufel@med.uni-muenchen.de

M. Habs

e-mail: maximilian.habs@med.uni-muenchen.de

R. Feuerecker

e-mail: regina.feuerecker@med.uni-muenchen.de

C. Muth

e-mail: carolin.muth@med.uni-muenchen.de

T. Klopstock

e-mail: thomas.klopstock@med.uni-muenchen.de of $16.1 \pm 7.1$ to $12.8 \pm 6.8$ (mean $\pm \mathrm{SD}$ ) on medication. There were also significant improvements in sub-scores for gait $(p=0.022), \quad$ speech $(p=0.007), \quad$ finger-chase $(p=0.042)$, nose-finger-test $(p=0.035)$, rapid-alternating-movements $(p=0.002)$ and heel-to-shin $(p=0.018)$. Furthermore, patients showed better performance in the SCAFI consisting of the 8 -m-walking-time $(8 \mathrm{MW}$, $p=0.003)$, 9-Hole-Peg-Test of the dominant hand (9HPTD, $p=0.011)$ and the PATA rate $(p=0.005)$. Quality of life increased during treatment $(p=0.003)$. No side effects were reported. In conclusion, acetyl-DL-leucine significantly improved ataxic symptoms without side effects and therefore showed a good risk-benefit profile. These findings need to be confirmed in placebo-controlled trials.

Keywords Ataxia - Cerebellum - Cerebellar ataxia . Acetyl-DL-leucine $\cdot$ Pharmacotherapy

K. Feil

e-mail: katharina.feil@med.uni-muenchen.de

B. P. van de Warrenburg

Department of Neurology, Donders Institute for Brain,

Cognition, and Behaviour, Radboud University Nijmegen

Medical Centre, Nijmegen, Netherlands

e-mail: B.vandeWarrenburg@ neuro.umcn.nl

T. Klopstock

Friedrich-Baur-Institute, German Network for Mitochondrial

Disorders (mitoNET) and German Center for Neurodegenerative

Diseases-DZNE, Munich, Germany 


\section{Introduction}

Cerebellar ataxia is a frequent and often-disabling syndrome that is mainly characterized by limb and gait ataxia as well as speech and ocular function impairment. In the majority of cases, it is caused by progressive heredodegenerative disorders [1]. So far, treatment of cerebellar ataxia has remained a difficult task as no medication has yet been proven really effective. There were attempts in the past to treat cerebellar signs, for example downbeat nystagmus (DBN) [2], episodic ataxia type 2 (EA2) [3], or cerebellar gait ataxia [4] with aminopyridines. Physiotherapy is recommended and applied in clinical practice but has only moderate effects [5-7]. Therefore, new drugs are needed, as cerebellar ataxia often leads to a significant disability of the affected patients.

Since 1957, acetyl-DL-leucine (Tanganil; Pierre Fabre, Castres, France), an acetylated derivative of a natural amino acid, has been widely used-mainly in France-for the symptomatic treatment of acute vertigo and dizziness and to improve central vestibular compensation [8]. Clinical experience has shown that it is a well-tolerated and safe drug without serious adverse effects [9-11].

Electrophysiological measurements have demonstrated that acetyl-DL-leucine modulates the activity of central vestibular neurons by normalizing the membrane potential of depolarized or hyperpolarized neurons [12], a mechanism that may lead to the observed improvement of central compensation. Furthermore, clinical studies with branchedchain amino acids demonstrated a symptomatic improvement of cerebellar symptoms [13]. As acetyl-DL-leucine is a branched-chain amino acid and in view of the phylogenetic and electrophysiological similarities and close interactions between vestibular and cerebellar neurons [14], we hypothesized that this agent might have a positive effect on ataxic symptoms in cerebellar disorders.

\section{Design/methods}

Thirteen patients (eight males; median age 51 years, range 13-68; median symptom duration 3 years, range 2-25 years; for further details see Table 1) were treated with acetyl-DL-leucine $5 \mathrm{~g}$ /day without titration $(500 \mathrm{mg}$ tablets of Tanganil) for 7 days. All patients gave their informed consent for the compassionate use of acetyl-DLleucine. The measurements were based on the Scale for the Rating and Assessment of Ataxia (SARA) [15, 16], an eight-item clinical rating scale (gait, stance, sitting, speech, coordination; range 0-40), and the Spinocerebellar Ataxia Functional Index (SCAFI) [17, 18], which consists of the 8-m-walking-time (8MW), 9-Hole-Peg-Test (9HPT) for appendicular function and the number of "PATA" repetitions over $10 \mathrm{~s}$ (PATA). These tests were performed at baseline and during treatment (on day $9 \pm 3$ days).

Quality of life during this symptomatic treatment was evaluated by using the Euro-Qol-5D-3L questionnaire (EQ5D-3L) [19]. Patients were asked about their subjective improvement on medication. The known side effects such as skin reactions (rash, urticaria, itching) were also systemically evaluated. Statistical analysis was performed using SPSS (IBM, Armonk, NY). Figures were designed with GraphPad Prism (v5, GraphPad Software Inc., La Jolla, CA, USA). Differences were considered significant if $p<0.05$. As data were not normally distributed, nonparametric testing was performed (Wilcoxon signed-rank test) with a Bonferroni correction.

\section{Results}

The clinical characteristics of the patients are given in Table 1. Thirteen patients with cerebellar disorders of different etiologies were observed (since patient no. 1 did not perform the SCAFI, he was excluded from the statistical analysis of this test). Mean duration of cerebellar symptoms was $8.5 \pm 6.8$ years. Mean total SARA decreased from a baseline of $16.1 \pm 7.1$ to $12.8 \pm 6.8$ $(p=0.002$, Wilcoxon signed-rank test). During treatment the SARA subsection scores were notably lower for gait ( $p=0.022)$, speech disturbance $(p=0.007)$, finger-chase $(p=0.042)$, nose-finger-test $(p=0.035)$, rapid-alternating-hand-movements $(p=0.002)$ and heel-shin-slide $(p=0.018)$ (Table 2; Figs. 1, 2). The SCAFI items also improved, represented by the $8 \mathrm{MW}(p=0.003)$, the 9HPT of the dominant hand $(p=0.011)$ and the PATA rate $(p=0.005)$. Moreover, the EQ-5D-3L changed from a baseline of $10.7 \pm 1.6$ to $9.5 \pm 2.0(p=0.003)$, indicating that quality of life was higher during treatment. The visual analogue scale (VAS) - as part of the EQ-5D-3L-rose from $0.57 \pm 0.21$ to $0.63 \pm 0.19(p=0.241)$. Eleven out of 13 patients reported a subjective improvement on therapy (nos. 1, 3, 4, 6, 7, 8, 9, 10, 11, 12, 13). The patients did not report any side effects.

\section{Discussion}

The 13 patients in this case series had ataxia as the leading symptom of cerebellar disorders of different etiologies. Patients on medication with acetyl-DL-leucine showed a significant improvement of both the ataxic symptomsmeasured by SARA and SCAFI-as well as quality of life. The daily administration of $5 \mathrm{~g} /$ day used in this case series is in the upper range of the drug's recommended dosage, but lower than in studies on its use for acute vertigo [8 g/ 
Table 1 Patient characteristics, categorized by patient number, gender, age, etiology, age at onset, duration of disease, MRI, and neuroophthalmological findings

\begin{tabular}{|c|c|c|c|c|c|c|c|}
\hline Patient no. & Sex & Age & Type & $\begin{array}{l}\text { Age at } \\
\text { onset }\end{array}$ & $\begin{array}{l}\text { Duration } \\
\text { (in years) }\end{array}$ & Brain MRI findings & Neurological findings \\
\hline 1 & Male & 60 & SAOA & 58 & 2 & Normal & $\begin{array}{l}\text { 1, } 5 \text { (unilateral), } 6,7 \text {, horizontal hypermetric } \\
\text { saccades, square wave jerks }\end{array}$ \\
\hline 2 & Male & 51 & SAOA & 48 & 3 & Normal & $1,2,3,6,7$ hypometric saccades \\
\hline 3 & Male & 54 & SAOA & 51 & 3 & Normal & $1,2,7,8$ \\
\hline 4 & Female & 63 & SAOA & 38 & 25 & Atrophy of vermis & $1,2,3,4,6,7$ \\
\hline 5 & Male & 23 & SCA2 & 20 & 3 & Atrophy of cerebellum & $1,2,7$, slow saccades \\
\hline $6^{\mathrm{a}}$ & Female & 57 & $\mathrm{ADCA}$ & 44 & 9 & Atrophy of the vermis & 1,3 \\
\hline $7^{\mathrm{a}}$ & Female & 68 & ADCA & 54 & 14 & Atrophy of the vermis & $\begin{array}{l}1,2,3,6,7,8, \text { hypometric saccades, SVV } \\
\text { deviation }\end{array}$ \\
\hline 8 & Female & 47 & SCA1 & 44 & 3 & Atrophy of the cerebellum & $1,2,5$ (bilateral), 6,7 , hypermetric saccades \\
\hline 9 & Female & 56 & SAOA & 54 & 2 & $\begin{array}{l}\text { Atrophy of the vermis and } \\
\text { anterior lobe }\end{array}$ & 1,6 \\
\hline $10^{\mathrm{b}}$ & Male & 25 & $\mathrm{AOA}$ & 12 & 13 & Atrophy of cerebellum & $\begin{array}{l}1,2,7 \\
\text { PNP, muscle atrophy, dysarthrophonia, ocular } \\
\text { apraxia }\end{array}$ \\
\hline $11^{\mathrm{b}}$ & Male & 23 & AOA & 11 & 12 & Atrophy of cerebellum & $\begin{array}{l}1,2,7 \\
\text { PNP, muscle atrophy, dysarthrophonia, ocular } \\
\text { apraxia }\end{array}$ \\
\hline $12^{\mathrm{b}}$ & Male & 19 & $\mathrm{AOA}$ & 10 & 9 & Atrophy of cerebellum & $\begin{array}{l}1,7 \\
\text { PNP, muscle atrophy, dysarthrophonia, ocular } \\
\text { apraxia }\end{array}$ \\
\hline $13^{\mathrm{b}}$ & Male & 13 & $\mathrm{AOA}$ & 11 & 2 & Atrophy of cerebellum & $\begin{array}{l}7 \\
\text { Dysarthrophonia }\end{array}$ \\
\hline
\end{tabular}

$A O A$ Ataxia with oculomotor apraxia (AOA1 and AOA2 genetically excluded), SAOA sporadic adult-onset ataxia of unknown etiology, $A D C A$ autosomal dominant cerebellar ataxia, $S V V$ subjective visual vertical, $P N P$ polyneuropathy, 1 saccadic smooth pursuit, 2 gaze-evoked nystagmus, 3 head-shaking nystagmus, 4 rebound nystagmus, 5 pathological head-thrust test (uni- or bilateral), 6 impaired visual fixation suppression of the VOR, 7 pathological optokinetic reflex, 8 downbeat nystagmus

${ }^{a}$ Relatives of family one (cousins)

b Relatives of family two (siblings)

day; for reference see (https://www.clinicaltrialsregister.eu/ ctr-search/trial/2010-023099-13/DE)]. As expected from its safety profile, acetyl-DL-leucine was well tolerated; patients did not report any side effects.

Currently there is no proven symptomatic pharmacotherapy for cerebellar ataxias. Drugs such as varenicline [20], riluzole [21] or erythropoietin in Friedreich's ataxia [22] were tested in the past. In a placebo-controlled trial with varenicline SCA3 patients showed an improvement of -1.97 SARA points compared to -0.86 on placebo [20]. As mentioned above, aminopyridines are effective in a subset of symptoms (DBN [2] or EA2 [3]). Because there are no effective anti-ataxia drugs, current standard treatment recommendations mainly include physiotherapy [5, 7]. The improvement of function after 4 weeks of intensive physiotherapy was -5.2 SARA points [5]; patients regained functional performance equivalent to that after two or more years of disease progression. The natural disease progression of degenerative cerebellar ataxias is
0.6-2.5 SARA points per year [5]. Compared to this, patients on treatment with acetyl-DL-leucine had an improvement of -3.3 SARA points after treatment for $9 \pm 3$ days. It has to be mentioned that the patient group in this case series was inhomogeneous-so it is probable that the positive effects might be even be better in a more homogenous group of patients.

Although acetyl-DL-leucine has been in use for more than 50 years, its exact pharmacological and electrophysiological modes of action have not been fully elucidated. An animal model of acute unilateral labyrinthectomy in guinea pigs showed that acetyl-DL-leucine restored the membrane potential of both hyperpolarized and depolarized vestibular neurons $[8,12]$. This effect is assumed to be mediated by its direct interactions with membrane phospholipids [11] such as phosphatidylinositol 4,5-bisphosphate, which influences ion channel activity [23]. On the basis of these findings, acetyl-DL-leucine may also stabilize the membrane potential of cerebellar neurons. The input 
Table 2 Clinical assessment of patients by SARA and SCAFI at baseline and on medication

\begin{tabular}{|c|c|c|c|c|c|c|c|c|c|c|}
\hline \multirow[t]{2}{*}{ Patient no. } & \multicolumn{5}{|c|}{ Baseline } & \multicolumn{5}{|c|}{ On medication } \\
\hline & SARA & $8 \mathrm{MW}$ & PATA & 9HPT-D & 9HPT-N & SARA & $8 \mathrm{MW}$ & PATA & 9HPT-D & 9HPT-N \\
\hline 1 & 13.00 & $--^{c}$ & $-^{\mathrm{c}}$ & $-^{\mathrm{c}}$ & $-^{\mathrm{c}}$ & 9.00 & $-^{\mathrm{c}}$ & $--^{c}$ & $--^{c}$ & $-^{\mathrm{c}}$ \\
\hline 2 & 14.00 & 5.10 & 20.00 & 32.00 & 38.00 & 12.00 & 4.80 & 26.00 & 21.00 & 41.00 \\
\hline 3 & 12.00 & 4.90 & 14.00 & 41.20 & 38.20 & 9.50 & 4.70 & 22.00 & 37.80 & 33.80 \\
\hline 4 & 11.50 & 8.60 & 15.00 & 28.80 & 30.40 & 7.00 & 8.10 & 24.00 & 26.80 & 27.10 \\
\hline 5 & 13.00 & 5.20 & 23.00 & 41.40 & 40.70 & 9.00 & 4.40 & 23.00 & 30.40 & 29.90 \\
\hline $6^{\mathrm{a}}$ & 8.00 & 6.60 & 16.00 & 25.90 & 25.40 & 6.00 & 6.00 & 24.00 & 24.60 & 25.40 \\
\hline $7^{\mathrm{a}}$ & 17.00 & 10.10 & 19.00 & 37.60 & 40.70 & 11.00 & 8.00 & 22.00 & 29.70 & 38.70 \\
\hline 8 & 17.00 & 14.60 & 24.00 & 62.00 & 49.80 & 12.50 & 12.70 & 25.00 & 59.10 & 51.70 \\
\hline 9 & 13.00 & 6.70 & 14.00 & 45.00 & 30.70 & 12.00 & 6.50 & 26.00 & 35.70 & 27.80 \\
\hline $10^{\mathrm{b}}$ & 27.00 & $-{ }^{\mathrm{d}}$ & 11.00 & $-{ }^{\mathrm{d}}$ & $-{ }^{\mathrm{d}}$ & 27.00 & $--^{\mathrm{d}}$ & 11.00 & $-{ }^{\mathrm{d}}$ & $-{ }^{\mathrm{d}}$ \\
\hline $11^{\mathrm{b}}$ & 27.00 & 62.20 & 17.00 & $--^{\mathrm{d}}$ & $-{ }^{\mathrm{d}}$ & 23.00 & 44.00 & 18.00 & $-{ }^{\mathrm{d}}$ & $-{ }^{\mathrm{d}}$ \\
\hline $12^{\mathrm{b}}$ & 29.00 & 28.60 & 11.00 & $-{ }^{\mathrm{d}}$ & $-{ }^{\mathrm{d}}$ & 22.00 & 27.30 & 13.00 & $-{ }^{\mathrm{d}}$ & $-^{\mathrm{d}}$ \\
\hline
\end{tabular}

SARA Scale for the Assessment and Rating of Ataxia, SCAFI Spinocerebellar Ataxia Functional Index, 8 MW 8-m-walking-time, 9HPTD 9-Hole Peg Test of the dominant hand, 9HPTN 9-Hole Peg Test of the non-dominant hand

${ }^{\text {a }}$ Relatives of family one (cousins)

b Relatives of family two (siblings)

c Not performed for other reasons

${ }^{\mathrm{d}}$ Not able to perform due to disabling reasons
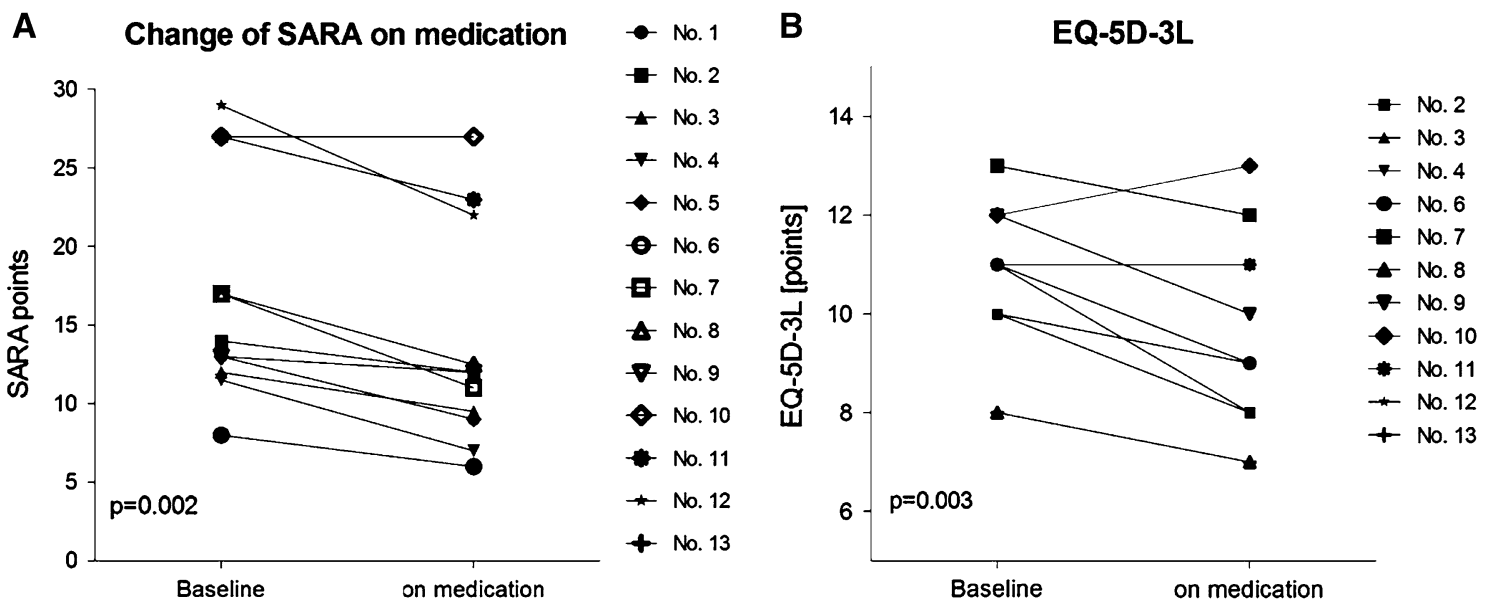

Fig. 1 Individual changes on a Scale for the Rating and Assessment of Ataxia (SARA) and b Quality of Life Questionnaire Euro-Qol-5D-3L (EQ-5D-3L) on medication with acetyl-DL-leucine ( $5 \mathrm{~g} /$ day) for $9 \pm 3$ days

from cerebellar Purkinje cells and mossy/climbing fiber collaterals controls the action potential of cerebellar and vestibular nuclei [24], which in turn project to the brainstem, thalamus and spinal cord [14]. Thus, acetyl-DL-leucine may act through afferent and efferent projections on upstream and downstream structures, thereby influencing motor control. It may also influence adaptive mechanisms throughout the vestibular-cerebellar network and be involved in the balancing of information between the cerebellum and effector muscles. However, the modes of action of acetyl-DL-leucine in cerebellar disorders are still largely hypothetical and require further research. Our clinical findings on its efficacy in cerebellar ataxia must be carefully evaluated in electrophysiological studies and animal models of cerebellar ataxia as well as placebocontrolled and PET imaging studies in humans.

Clearly this case series has several limitations. First, this is not a randomized, placebo-controlled trial. Second, the change in the symptoms after termination of the treatment was not systematically evaluated. Third, we cannot rule out either a placebo effect or a training effect on components of the ataxia assessment (e.g., 9HPT), but neither effect can 
Fig. 2 Value changes on a Scale for the Assessment and Rating of Ataxia (SARA) and Spinocerebellar Ataxia Functional Index (SCAFI) subscore items in terms of $\mathbf{b} 8 \mathrm{~m}$ walk (8 MW), c PATA word count in $10 \mathrm{~s}$ and $\mathbf{d}$ 9-hole-pegtest (9HPT) of the dominant and non-dominant hand before and during the therapy with acetylDL-leucine (5 g/day) (mean $\pm \mathrm{SD})$
A
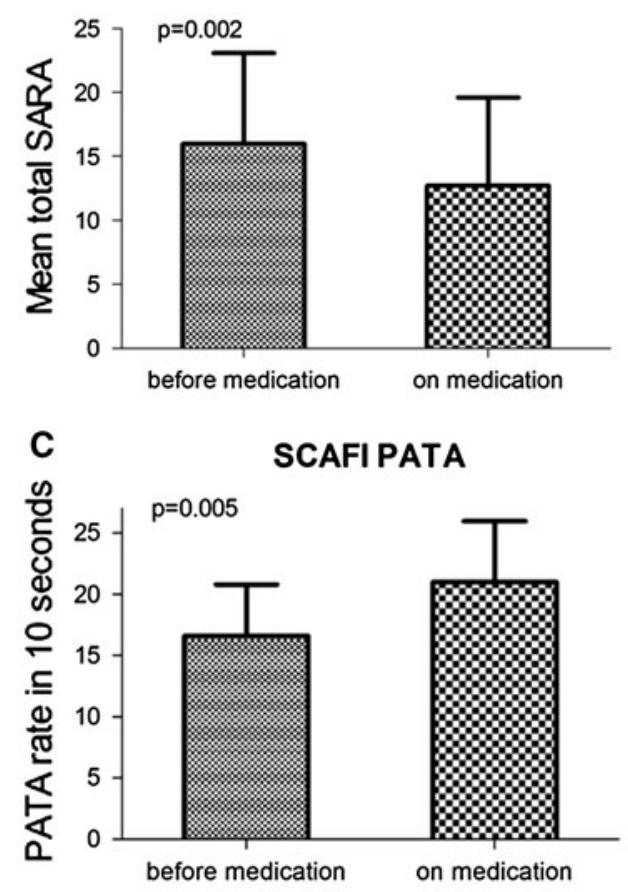

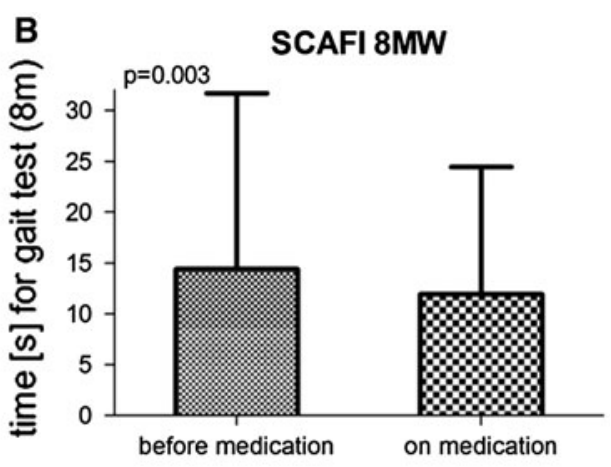

D

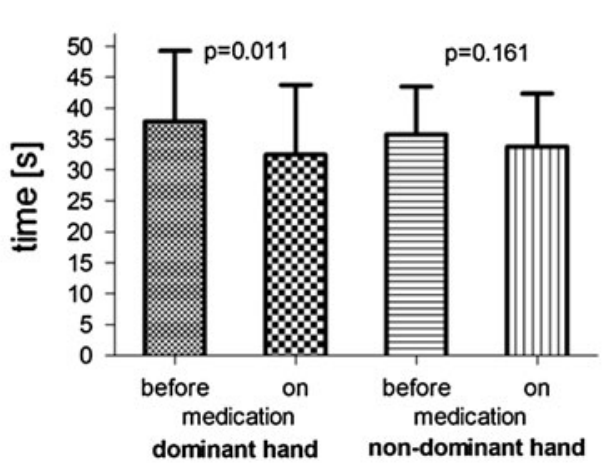

explain the significant and clinically convincing effects documented by the standard ataxia scores SARA and SCAFI. In conclusion, its improvement of cerebellar ataxia and the absence of adverse effects indicate that acetyl-DLleucine is a worthy candidate for further clinical trials and also basic research.

Acknowledgments We thank Judy Benson and Katie Ogston for copy-editing the manuscript. We thank the patients and their relatives for their contribution to this study, in particular the mother of the four siblings. This study was supported by the BMBF to the IFB (grant code 01 EO 0901).

Conflicts of interest M. Strupp is Joint Chief Editor of the Journal of Neurology, Editor in Chief of Frontiers of Neuro-otology and Section Editor of F1000. He has received speaker's honoraria from Abbott, Actelion, UCB, GSK, CSC, TEVA, Biogen Idec, PierreFabre, Eisai and Hennig Pharma. He has received research support from government entities (German Research Foundation (DFG) and the German Federal Ministry of Education and Research (BMBF)) and from commercial entities (Biogen Idec, Pierre-Fabre, Actelion). He has served on scientific advisory boards for commercial entities (Abbott, Pierre-Fabre, Biogen Idec, Bayer Pharmaceuticals).

K. Feil, M. Habs, R. Feuerecker, C. Muth, and J. Teufel report no disclosures.

T. Klopstock has been a principal investigator or investigator on industry-sponsored trials funded by Santhera Pharmaceuticals Ltd (idebenone in LHON, idebenone in Friedreich ataxia) and by $\mathrm{H}$. Lundbeck A/S (carbamylated erythropoietin in Friedreich ataxia). He has received research support from government entities (German Research Foundation; German Federal Ministry of Education and Research; European Commission 7th Framework Programme) and from commercial entities (Santhera Pharmaceuticals Ltd; Actelion
Pharmaceuticals Ltd; H. Lundbeck A/S). He has served on scientific advisory boards for commercial entities (Santhera Pharmaceuticals Ltd; Actelion Pharmaceuticals Ltd) and for non-profit entities (Center for Rare Diseases Bonn, Germany; Hoffnungsbaum e.V., Germany). $\mathrm{He}$ has received speaker honoraria and travel expenses from commercial entities (Dr. Willmar Schwabe GmbH \& Co. KG; Eisai Co., Ltd.; Santhera Pharmaceuticals Ltd; Actelion Pharmaceuticals Ltd; Boehringer Ingelheim Pharma GmbH \& Co. KG, GlaxoSmithKline $\mathrm{GmbH} \&$ Co. KG). He has been a consultant for Gerson Lehrman Group, USA, and FinTech Global Capital, Japan. He has served as a Section Editor for BMC Medical Genetics since 2011.

B. van de Warrenburg is supported by grants from the Gossweiler Foundation, Netherlands Brain Foundation, Radboud University Nijmegen Medical Centre, Royal Dutch Society for Physical Therapy, and the Dutch Biobanking and Biomolecular Resources Research Infrastructure (BBMRI).

Ethical Standards All human studies must state that they have been approved by the appropriate ethics committee and have therefore been performed in accordance with the ethical standards laid down in the 1964 Declaration of Helsinki.

Open Access This article is distributed under the terms of the Creative Commons Attribution License which permits any use, distribution, and reproduction in any medium, provided the original author(s) and the source are credited.

\section{References}

1. Manto M, Marmolino D (2009) Cerebellar ataxias. Curr Opin Neurol 22:419-429 
2. Strupp M, Schuler O, Krafczyk S et al (2003) Treatment of downbeat nystagmus with 3,4-diaminopyridine: a placebo-controlled study. Neurology 61:165-170

3. Strupp M, Kalla R, Claassen J et al (2011) A randomized trial of 4-aminopyridine in EA2 and related familial episodic ataxias. Neurology 77:269-275

4. Schniepp R, Wuehr M, Neuhaeusser M et al (2012) 4-Aminopyridine and cerebellar gait: a retrospective case series. J Neurol 259:2491-2493

5. Ilg W, Synofzik M, Brotz D, Burkard S, Giese MA, Schols L (2009) Intensive coordinative training improves motor performance in degenerative cerebellar disease. Neurology 73:1823-1830

6. Klockgether T (2005) Ataxias. Diagnostic procedure and treatment. Nervenarzt 76:1275-1283

7. Raitano AB, Halpern JR, Hambuch TM, Sawyers CL (1995) The Bcr-Abl leukemia oncogene activates Jun kinase and requires Jun for transformation. Proc Natl Acad Sci USA 92:11746-11750

8. Ferber-Viart C, Dubreuil C, Vidal PP (2009) Effects of acetyl-DLleucine in vestibular patients: a clinical study following neurotomy and labyrinthectomy. Audiol neuro-otol 14:17-25

9. Lacour M (1995) Influence d'un traitement pharmacologique à l'acétyl-DL-leucine dans la compensation des déficits vestibulaires chez le chat. Dissertation/report. Rapport de fin d'études établit pour les Laboratoires Pierre Fabre. Pierre Fabre Médicaments, Castres

10. Léger A, Schnerb A, Lejeune D, Glisse J-C, Vieillefond H (1986) Effet de l'acétyl-DL-leucine sur les caractéristiques du réflexe vestibulooculaire per- et post-rotatoire. Médecine des armées 13:269-273

11. Neuzil E, Ravaine S, Cousse H (2002) La N-acétyl-DL-leucine, médicament symptomatique de vertigineux. Bulletin de la société de pharmacie de Bordeaux 141:15-38

12. Vibert N, Vidal PP (2001) In vitro effects of acetyl-DL-leucine (Tanganil) on central vestibular neurons and vestibulo-ocular networks of the guinea-pig. Eur J Neurosci 13:735-748
13. Mori M, Adachi Y, Mori N et al (2002) Double-blind crossover study of branched-chain amino acid therapy in patients with spinocerebellar degeneration. J Neurol Sci 195:149-152

14. Highstein SM, Holstein GR (2006) The anatomy of the vestibular nuclei. Prog Brain Res 151:157-203

15. Subramony SH (2007) SARA - a new clinical scale for the assessment and rating of ataxia. Nat Clin Pract Neurol 3:136-137

16. Weyer A, Abele M, Schmitz-Hubsch T et al (2007) Reliability and validity of the scale for the assessment and rating of ataxia: a study in 64 ataxia patients. Mov Disord 22:1633-1637

17. Schmitz-Hubsch T, du Montcel ST, Baliko L et al (2006) Scale for the assessment and rating of ataxia: development of a new clinical scale. Neurology 66:1717-1720

18. Schmitz-Hubsch T, Giunti P, Stephenson DA et al (2008) SCA functional index: a useful compound performance measure for spinocerebellar ataxia. Neurology 71:486-492

19. Rabin R, de Charro F (2001) EQ-5D: a measure of health status from the EuroQol group. Ann Med 33:337-343

20. Zesiewicz TA, Greenstein PE, Sullivan KL et al (2012) A randomized trial of varenicline (Chantix) for the treatment of spinocerebellar ataxia type 3. Neurology 78:545-550

21. Ristori G, Romano S, Visconti A et al (2010) Riluzole in cerebellar ataxia: a randomized, double-blind, placebo-controlled pilot trial. Neurology 74:839-845

22. Boesch S, Sturm B, Hering S et al (2008) Neurological effects of recombinant human erythropoietin in Friedreich's ataxia: a clinical pilot trial. Mov Disord 23:1940-1944

23. Suh BC, Hille B (2008) PIP2 is a necessary cofactor for ion channel function: how and why? Annual Rev Biophys 37: 175-195

24. Witter L, De Zeeuw CI, Ruigrok TJ, Hoebeek FE (2011) The cerebellar nuclei take center stage. Cerebellum 10:633-636 